\title{
Das Appellationsgericht in Prag 1548-1783 Forschung, Quellen und historische Entwicklung
}

\section{Bisherige Erforschung der Geschichte des Appellationsgerichts in Prag}

Die Anfänge der Erforschung der Geschichte des Appellationsgerichts (Rates für Appellationen) in Prag in der böhmischen bzw. mitteleuropäischen (nicht nur Rechts-)Historiographie reichen bis in das beginnende 19. Jahrhundert zurück. Mit Ausnahme der letzten vier Dezennien wurde diese Forschung aber nicht sehr intensiv betrieben.

Die erste der Geschichte des Appellationsgerichts in Prag gewidmete Arbeit entstand schon Anfang des 19. Jahrhunderts. Ihr Autor war der spätere Präsident des Appellationsgerichts für Mähren und Schlesien in Brünn, Josef Graf von Auersperg (1767-1829), der zur Zeit der Abfassung seines Werkes als Rat am Prager Appellationsgericht wirkte. ${ }^{1}$ Eine wesentlich umfassendere und im Hinblick auf die Fakten zuverlässigere Geschichte des Prager Appellationsgerichts schrieb anlässlich der dreihundertsten Wiederkehr seiner Gründung der Appellationsrat Johann Ferdinand Schmidt (später von Bergenhold) (1786-1873). ${ }^{2}$ Bergenholds Arbeit umfasste die gesamte mehr als 300-jährige Geschichte des Appellationsgerichts. Die bis heute verwendete Periodisierung dieser Geschichte geht auf Bergenholds Vorschlag zurück. Danach werden

\footnotetext{
${ }^{1}$ AuERsPerG, Geschichte.

2 SCHMIDT, Monographie.
}

drei Zeitabschnitte unterschieden: 1. von der Errichtung des Appellationsgerichts im Januar 1548 bis zu seiner Reform im November 1644; 2. von 1644 bis zur Umwandlung des Appellationsgerichts in das Allgemeine Appellationsgericht im Jahre 1783; 3. von 1783 bis zum Jahre 1850, in dem das Allgemeine Appellationsgericht in das Oberlandesgericht umgewandelt wurde. ${ }^{3}$

Im Jahre 1933 erschien eine umfassende, in Tschechisch verfasste Publikation über die Geschichte des Prager Appellationsgerichts. Ihr Autor, der Bibliothekar am Obersten Gericht in Prag Václav Zdeněk, behandelte nicht nur die Entwicklung des Appellations- bzw. Allgemeinen Appellationsgerichts seit 1548 bis 1783 bzw. 1850, sondern befasste sich auch mit der Entwicklung, die seine unmittelbaren Nachfolger, das Oberlandesgericht bzw. das Obergericht in Prag, nahmen. ${ }^{4}$ Die bisher beste Bearbeitung der Geschichte des Appellationsgerichts in Prag, was die erste Periode seiner Existenz, d.h. die Jahre 1548-1644 anbelangt, ist die nicht im Druck erschienene Diplomarbeit des späteren Archivars Ivo Plecháček (1931-1990) aus den 1950er Jahren. ${ }^{5}$

\footnotetext{
${ }^{3}$ Ebd. Vgl. auch PLECHÁČEK, Apelační soud 6f.

${ }^{4}$ ZDENĚK, Dějiny král. Apellačního soudu.

${ }^{5}$ PLECHÁČEK, Apelační soud. Plecháčeks bedeutende Arbeit ist leider in den folgenden Dezennien in erheblichem Maße in Vergessenheit geraten. Weder ADAMOVÁ, Apelační soud, noch RYANTOVÁ, Ladislav II.,
} 
$\mathrm{Zu}$ der am häufigsten zitierten tschechischen Arbeit über die Entwicklung des Appellationsgerichts in Prag im ersten Jahrhundert seines Bestehens, namentlich in den Jahren 1548-1651, wurde aber - man kann hier fast von einem Paradox sprechen - die relativ gedrängte Übersicht aus der Feder der späteren Professorin für Rechtsgeschichte an den Juristenfakultäten der Karlsuniversität Prag und der Westböhmischen Universität Pilsen, Karolina Adamová (geb. 1948), die im Jahre 1975 erschien. ${ }^{6}$ Die Autorin ging, was die historischen Fakten betrifft, größtenteils von der älteren Literatur, vor allem dem Buch Schmidts, aus. Im Hinblick auf die Quellen beschränkte sie sich (im Gegensatz zu Plecháček, ${ }^{7}$ dessen Arbeit sie nicht kennt) bis auf eine einzige Ausnahme auf die Auswertung von normativen Quellen. Als terminus ad quem ihrer Studie wählte Adamová nicht das Jahr 1644, sondern 1651; in diesem Jahr wurde die sog. Hauptmannschaft der deutschen Lehen (deutsche Lehenhauptmannschaft, Lehenschranne) ${ }^{8}$ aufgehoben.

Dem Appellationsgericht wurde auch unterschiedlich große Aufmerksamkeit in allen seit der zweiten Hälfte des 19. Jahrhunderts bis in die Gegenwart erschienenen monographischen Bearbeitungen der böhmischen Rechts- und Verwaltungsgeschichte und der Geschichte der Gerichtsbarkeit zuteil. ${ }^{9}$

haben diese Arbeit gekannt. Dasselbe gilt für HAUSENBLASOVÁ, Počátky.

${ }^{6}$ ADAMOVÁ, Apelační soud.

7 PLECHÁČEK, Apelační soud.

${ }^{8}$ Es handelte sich hierbei um ein Amt und zugleich ein Lehengericht, das seit dem Ende des 15. Jahrhunderts die Agenden der auswärtigen Lehen der Böhmischen Krone bearbeitete. Diese Agenden wurden im Jahre 1651 an das Prager Appellationsgericht übertragen, dazu VeSELÝ, O přenesení působnosti. Ausführlicher siehe unten 243.

${ }^{9}$ D'ELVERT, Zur Oesterreichischen VerwaltungsGeschichte 190-192; KALOUSEK, České státní právo 116, 121f., 294f., 447, 484; ČELAKOVSKÝ, Povšechné právní dějiny české 123, 131, 187, 191; KAPRAS, Právní
Die Geschichte des Appellationsgerichts, insbesondere was das 16. und 17. Jahrhundert anbelangt, erregte auch das Interesse der Autoren einiger anderer Monographien, wobei es sich allerdings vorwiegend um rechtshistorische Werke handelt. Die beste, bis in die Mitte des 20. Jahrhunderts unübertroffene zusammenhängende Darstellung der Geschichte des Appellationsgerichts legte der Professor an der Prager Juristenfakultät Emil Ott (1845-1924) in seinem grundlegenden Werk über die Rezeption des römisch-kanonischen Prozesses in den böhmischen Ländern vor. ${ }^{10}$ Relativ große Aufmerksamkeit widmete der Tätigkeit des Appellationsgerichts als Berufungsinstanz der Stadtgerichte in der Zeit vor der Schlacht am Weißen Berg auch Zikmund Winter (1846-1912) in seiner Monographie über die böhmischen Städte, ${ }^{11}$ wobei er aber sehr unsystematisch verfuhr.

Ein neues, wesentlich intensiveres Interesse für das Appellationsgericht in Prag lässt sich seit ungefähr der Mitte der 1970er Jahre beobachten. Dieses Interesse an dem Appellationsgericht und seinem Schriftgut, insbesondere an den sog. Urteilsmanualen, wurde aber nicht von der Übersicht Adamovás ${ }^{12}$ geweckt, sondern durch die Forschungen zur Halsgerichtsbarkeit im südlichen Teil Mittelböhmens, die seit der ersten Hälfte der 1970er Jahre durch den späteren Professor für böhmische und tschechoslowakische Geschichte an der Philosophischen Fakultät der Karlsuniversität und geradezu zum Klassiker

dějiny 2, 421f., 3, 199; DERS., Přehled právních dějin 156, 212; PETERKA, Rechtsgeschichte 98-100, 121f., 130, 166; BAXA, Dějiny práva 162, 204f.; Jiří KLABOUCH, Staré české soudnictví 134, 141-143, 228f.; VANĚČEK, Dějiny státu a práva 162f., 207, 243, 300f.; MALÝ, SIVÁK, Dějiny státu a práva 117f.; MALÝ, Dějiny českého a československého práva, insbes. 156; Bílý, Právní dějiny 209f.; JANÁK, HLEDÍKOvÁ, Dějiny správy 117f., 147, 192, 195-197, 252; JANÁK, HLEDÍKOVÁ, DOBEŠ, Dějiny správy, insbes. 99, 166-168, 218.

${ }^{10}$ OTт, Beiträge 210-228.

${ }^{11}$ WiNTER, Kulturní obraz 690-704.

12 Adamová, Apelační soud. 
gewordenen Exponenten der modernen tschechischen Forschung im Bereich der Kriminalitätsgeschichte, Jaroslav Pánek (geb. 1947), und die Archivarin Eva Procházková (geb. 1950) betrieben wurden. Auf der Grundlage ihrer Studien gelangten beide $\mathrm{zu}$ dem Schluss, dass die auf uns gekommenen Gerichtsbücher des Appellationsgerichts in Prag, vor allem die sog. Urteilsmanuale, eine bedeutsame komplementäre Quelle für die Beschäftigung mit der städtischen Halsgerichtsbarkeit und der Kriminalität in Böhmen in der Frühen Neuzeit darstellen.13 Sie seien vor allem eine Ergänzung zu den sog. Schwarzen Büchern (Pechbücher). ${ }^{14}$ Seit dem Ende der 1970er Jahre begannen auch andere Forscher, die sich mit der Geschichte der städtischen Halsgerichtsbarkeit und der Kriminalität in Böhmen beschäftigten, die Bücher des Appellationsgerichts als ergänzende Quelle zu verwerten. ${ }^{15}$

Seit Anfang der 1990er Jahre wurde es auf Grund der Ergebnisse der sich ständig intensivierenden und vertiefenden Erforschung der Geschichte der städtischen Straf- und Halsgerichtsbarkeit in Böhmen nichtsdestoweniger offensichtlich, dass man von den Büchern des Appellationsgerichts als Quelle für diese Thematik zu viel erwartet hatte und darüber hinaus zum Teil von falschen Vorstellungen ausgegangen war. Es zeigte sich, dass die Urteilsmanuale,

\footnotetext{
${ }^{13}$ Seine Erkenntnisse zur Arbeit mit den Büchern des Prager Appellationsgerichts formulierte PÁNEK zum ersten Mal in der Studie Hrdelní soudnictví města Příbramě, insbes. 90f. Zusammenfassend siehe auch DERS., Městské hrdelní soudnictví, sowie die verkürzte deutsche Version DERS., Die Halsgerichtsbarkeit der böhmischen Städte und Märkte. Diese Studien enthalten auch eine Übersicht über die bis Mitte der 1980er Jahre veröffentlichten Arbeiten Páneks und Procházkovás über die Geschichte der Halsgerichtsbarkeit.

${ }^{14}$ KREUZ, Stav a perspektivy.

${ }^{15}$ Eine Übersicht über diese bis zur ersten Hälfte der 1990er Jahre publizierten Arbeiten findet sich im Repertorium FRANCEK, ŠIMEK, Hrdelní soudnictví 134-178.
}

konkret aus der Zeit von der Mitte des 16. bis in das zweite Drittel des 17. Jahrhunderts, durchaus kein so bedeutsames Ensemble von komplementären Quellen für die Geschichte der städtischen Halsgerichtsbarkeit in Böhmen in der Frühen Neuzeit darstellen wie bisher angenommen worden war. Die von Pánek und Procházková formulierte Schlussfolgerung, dass die Urteilsmanuale in bedeutendem Maße imstande seien, die relativ sporadisch erhaltenen Pechbücher zu ersetzen, gilt erst seit dem letzten Viertel des 17. Jahrhunderts, also nur für das letzte Jahrhundert des Bestehens des Appellationsgerichts vor seiner Umwandlung in das Allgemeine Appellationsgericht im Jahre 1783. ${ }^{16}$ Vorher entschied das Appellationsgericht überwiegend, wenn nicht fast ausschließlich in Streitfällen, die vor den städtischen (ggf. auch anderen ${ }^{17}$ ) Gerichten im Akkusationsverfahren (also nicht im Inquisitionsverfahren) verhandelt worden waren, und in welchen eine der streitenden Parteien Berufung gegen das Gerichtsurteil eingelegt hatte. ${ }^{18}$ Mit der Verkündung der Verneuerten Landesordnung für das Königreich Böhmen (Obnovené zř́zení zemské) im Jahre 1627 wurde das Appellationsgericht zwar eindeutig mit umfassenden Befugnissen auch im Bereich der Halsgerichtsbarkeit ausgestattet, ${ }^{19}$ es gelang ihm aber erst im letzten Viertel des 17. Jahrhunderts, sie in der Praxis durchzusetzen. ${ }^{20}$ Erst in dieser

\footnotetext{
${ }^{16}$ Einen eindeutigen Beweis dieser Tatsache lieferten in jüngster Zeit die Forschungsergebnisse von RŮŽIČKOVÁ, SigLOVÁ, Apelační soud a odvolání.

${ }^{17}$ Insbes. den Patrimonialgerichten der Kammerdomänen und einigen Prager Gerichten, die ihrem örtlichen (Sonder-)Recht nach urteilten.

${ }^{18}$ Dazu sehr instruktiv RƯŽIČKOVÁ, SIGLOVÁ, Apelační soud a odvolání, insbes. 17.

${ }^{19}$ VLO, 500-503 (Art. R.VI-R.VIII), 508f. (Art. R.XVIII). Vgl. auch PLECHÁČEK, Apelační soud 45f.

${ }^{20}$ Auf diese Tatsache wies mit Recht bereits PÁNEK, Městské hrdelní soudnictví 707, hin, als er konstatierte, dass sich der Einfluss des Prager Rates für Appellationen erst am Ende des 17. Jahrhunderts geltend machen konnte.
} 
Zeit begann das Appellationsgericht, seine umfassenden Befugnisse auch wahrzunehmen, einschließlich der Vollmacht, alle von den Stadtgerichten (und eventuell anderen Gerichten) verhängten Todesurteile (d.h. die im Inquisitionsverfahren verkündeten Urteile) zu bestätigen. Erst seit dieser Zeit tauchen in den Urteilsbüchern des Prager Appellationsgerichts in einer größeren Zahl im Inquisitionsverfahren verhandelte Fälle auf, und erst von da an kann man diese Bücher als Komplementärquellen zu den Pechbüchern betrachten. ${ }^{21}$ Im Zusammenhang mit diesen Feststellungen gelangte die tschechische Forschung auf dem Gebiet der Geschichte der Halsgerichtsbarkeit hinsichtlich der Ergiebigkeit der Bücher (insbesondere der Urteilsbücher) des Prager Appellationsgerichts als einschlägige Quelle zu der seither allgemein akzeptierten Feststellung, dass ,ihre Bedeutung [...] vor allem darin bestehe, dass sie zum Teil die Rechtsgewohnheiten der Halsjurisdiktion sowie die soziale Stellung der Angeklagten und der Ankläger erkennen lassen, und einige Angaben liefern, die es ermöglichen, die Entwicklung der Stadtgerichte zu verfolgen“.22 Die Urteilsbücher des Appellationsgerichts stellen in der zeitgenössischen tschechischen Forschung weiterhin mit Recht eine nicht zu vernachlässigende und häufig verwertete Quelle zur Erforschung der Straf- und Halsgerichtsbarkeit in den einzelnen böhmischen Städten seit der Mitte des 16. Jahrhunderts bis zum Jahre 1765 dar. ${ }^{23}$

\footnotetext{
${ }^{21}$ KReUZ, Stav a perspektivy. In der Praxis wurde diese Tatsache schon von Eva Procházková in ihrer großangelegten Studie zur Verfolgung von RomaNomaden in Böhmen seit dem Ende des 17. Jahrhunderts bis zum Jahre 1765 belegt. Sie ging dabei von den Urteilsmanualen des Appellationsgerichts aus, PROCHÁzKOVÁ, Perzekuce romských kočovníků. Zu demselben Ergebnis kommen auch RŮŽIČKOVÁ, SigLOVÁ, Apelační soud a odvolání.

22 FRANCEK, Zločin a trest 39.

${ }^{23}$ Eine kommentierte Übersicht über den Stand der tschechischen Forschung zur Geschichte der Halsge-
}

Die tschechische Forschung hat in den letzten zwei Jahrzehnten einige andere wertvolle Beiträge zur Analyse des Wirkens und der Verwaltungsentwicklung des Appellationsgerichts in Prag geleistet. ${ }^{24}$ Das Anliegen dieser Arbeiten war aber meist nur die Erforschung der Epoche vor der Schlacht am Weißen Berg, also die Untersuchung der ersten sieben Dezennien des Bestehens des Gerichts. Eine Ausnahme stellt hier der Beitrag von Michaela Neudertová (= Hrubá) und Lenka Kuthanová dar, in dem die Autorinnen die Korrespondenz zwischen dem Appellationsgericht und dem Gericht der nordböhmischen königlichen Stadt Louny/Laun analysieren. ${ }^{25}$ Die Biographie des ersten Präsidenten des Appellationsgerichts, Ladislav (Ladislaus) II. Popel von Lobkowitz (1501-1584, Präsident in den Jahren 1548-1570), vor dem Hintergrund der ersten Jahrzehnte der Entwicklung des Gerichts ist Gegenstand eines Beitrags von Marie Ryantová. ${ }^{26}$ Den Anfängen des Prager Appellationsgerichts und seiner personellen Besetzung in den Jahren 1548-1627 widmete sich Jaroslava Hausenblasová. ${ }^{27}$ Mit ausgewählten Eintragungen in den Urteilsmanualen des Appellationsgerichts zwischen 1548 und 1740, die den Ellbogener Kreis betrafen, beschäftigte sich in einem kleineren Aufsatz Květoslava Haubertová. ${ }^{28}$

richtsbarkeit und der Kriminalität lieferte Ende der 1990er Jahre PROCHÁZKOVÁ, Současný stav.

${ }^{24}$ Ich lasse einige einschlägige rechtsgeschichtliche Diplomarbeiten bzw. Dissertationen zum Thema Appellationsgericht, die in den letzten zwei Dezennien an der Juristenfakultät der Karlsuniversität zu Prag bzw. an anderen Juristenfakultäten in der Tschechischen Republik verteidigt wurden, beiseite, weil es sich ausnahmslos um bloße Kompilationen handelt, deren fachlicher Beitrag gleich null ist.

${ }^{25}$ Neudertová, Kuthanová, Ke komunikaci apelačního soudu.

${ }^{26}$ RYANTOVÁ, Ladislav II. Leider entging der Aufmerksamkeit der Autorin die Arbeit von PLECHÁČEK, Apelační soud.

${ }^{27}$ Hausenblasová, Počátky.

${ }^{28}$ HAUBERTOVÁ, Loketsko. Der vor kurzem unternommene Versuch, die Geschichte des Appellations- 
Vor kurzem wurden die Bücher des Appellationsgerichts auch als Quelle zur Erforschung der Gerichtsbarkeit in den Städten verwertet, für die sich keine (oder fast keine) Gerichtsbücher örtlicher Provenienz erhalten haben. Dabei handelt es sich um die in methodischer Hinsicht vorbildhafte Arbeit von Lenka Kreuzová über die Gerichtsbarkeit der mittelböhmischen patrimonialen Kammerstadt Poděbrady im Zeitalter vor der Schlacht am Weißen Berge ${ }^{29}$ und um eine der Gerichtsbarkeit der mittelböhmischen königlichen Stadt Český Brod im selben Zeitraum gewidmete Arbeit aus der Feder von Hana Čadová. ${ }^{30}$ Eine Arbeit ähnlichen Typs, zeitlich aber etwas breiter angelegt und ein größeres Territorium umfassend, stellt die zweiteilige monographische Studie von Renáta Růžičková und Tereza Siglová dar. Diese wertvolle Arbeit bietet eine Übersicht und Analyse der gegen Urteile der Niedergerichte der Herrschaft Pardubice im 16.-18. Jahrhundert (1559-1782) beim Appellationsgericht eingelegten Berufungen (es handelt sich hierbei namentlich um Berufungen vom Gericht des Hauptmanns der genannten Herrschaft, von den Gerichten der Patrimonialstädte Pardubice und Přelouč und der patrimonalen Marktflecken Bohdaneč, Týnec, Sezemice und Dašice). ${ }^{31}$

Die neueste Arbeit von Bedeutung und im Hinblick auf die Fakten von großem Wert für die bisher mangelhaft erforschte Geschichte des Appellationsgerichts im 18. Jahrhundert stammt von Boris Šalak. ${ }^{32}$ Trotz seines Titels ist dieses gewichtige Werk zum einen der Entwicklung des Appellationsgerichts bis zum Jahre 1783, mit

gerichts in der Zeit vor der Schlacht am Weißen Berg neu $\mathrm{zu}$ behandeln, ist infolge der Unkenntnis der Arbeit von PlECHÁČEK, Apelační soud, zum größeren Teil entwertet, PLESKOT, Apelační soud.

${ }^{29}$ KreuZOVÁ, Agenda.

${ }^{30}$ ČADOVÁ, Soudnictví.

${ }^{31}$ RƯŽIČKOVÁ, Siglová, Apelační soud a odvolání; DIES., Apelační soud a př́ípady řešené.

32 ŠALAK, Apelační soud. zeitlichem Schwerpunkt in der zweiten Hälfte des 17. Jahrhunderts und im 18. Jahrhundert, ${ }^{33}$ und zum anderen der Entwicklung des Allgemeinen Appellationsgerichts in den Jahren 1783-1850 $0^{34}$ gewidmet. Šalaks eingehend und durchdacht strukturierte Arbeit bringt eine Reihe von wertvollen neuen Erkenntnissen über die Entwicklung und das Funktionieren des Appellationsgerichts insbesondere in der zweiten Hälfte des 17. Jahrhunderts und im 18. Jahrhundert. Eine interessante Bereicherung der bisher unvollständigen Erkenntnisse über Tätigkeit und Funktionsweise des Prager Appellationsgerichts in der zweiten Hälfte des 17. Jahrhunderts stellt in jüngster Zeit auch eine Studie von Klára Woitschowá dar. ${ }^{35}$

In den Jahren 2008-2010 bearbeitete Klára Woitschová, Assistentin am Lehrstuhl für historische Hilfswissenschaften und Archivistik an der Philosophischen Fakultät der Karlsuniversität zu Prag, ein umfassendes dreijähriges Einzelforschungsprojekt unter dem Titel Ortelní manuály a knihy protokolu apelačního soudu v Praze z let 1548-1783: Analýza a kritická edice (Urteilsmanuale und Protokollbücher des Appellationsgerichts in Prag aus den Jahren 1548-1783. Analyse und kritische Edition), das von der Forschungsförderungsagentur der Tschechischen Republik finanziert wurde. ${ }^{36}$ Hauptergebnis dieses Projekts ${ }^{37}$ sollte eine Datenbank ${ }^{38}$ der Eintragungen

\footnotetext{
${ }^{33}$ Ebd. 11-55.

${ }^{34}$ Ebd. 56-79.

${ }^{35}$ WoITSCHOVÁ, Obraz činnosti.

${ }^{36}$ Registraturnummer 407/08/0295,

[http://www.gacr.cz/statistiky/3/2010/4] (2010, abgerufen am: 6. 4. 2012).

37 Ihren Ausgangspunkt erläuterte WoITSCHOVÁ im Aufsatz Ortelní manuály. Die ersten Erfahrungen bei der Bearbeitung der Urteilsbücher und vorläufige Ergebnisse ihrer Forschungen fasste sie im Beitrag Edice zusammen. Vgl. auch DIES., Obraz činnosti.

${ }^{38}$ Nach der Projektleiterin Woitschová sollte es sich „um einen qualitativ neuen Typ einer Edition in Form einer elektronischen Datenbank" handeln, WOITSCHOVÁ, Ortelní manuály 551f.
} 
in den erhaltenen Urteilsbüchern des Appellationsgerichts in Prag aus den Jahren 1548-1783 bilden. Das Projekt wurde leider ohne ausreichende Kenntnis der zu bearbeitenden Quellen konzipiert und begutachtet ${ }^{39}$ und war in Umfang und Form, wie sie ursprünglich in Aussicht genommen worden waren, unrealisierbar. Das Projekt kann so höchstens und bestenfalls zu einem Ausgangspunkt der weiteren ErschlieBung und Bearbeitung der Bücher des Prager Appellationsgerichts werden. ${ }^{40}$

\section{Erhaltenes Schriftgut und Archivfonds des Appellationsgerichts in Prag}

Der Archivfonds „Appellationsgericht 15481783 (1809)“ wird gegenwärtig in der ersten Abteilung des Nationalarchivs in Prag aufbewahrt. ${ }^{41}$

Nach dem Untergang des Allgemeinen Appellationsgerichts im Jahre 1850 verblieb das Schriftgut des Appellationsgerichts in Prag (1548-1783) in der Registratur des neu errichteten Oberlandesgerichts in Prag, das zum Nachfolger des Allgemeinen Appellationsgerichts geworden war. ${ }^{42}$ Im Jahre 1868 wurde eine große Zahl der Bücher des Appellationsgerichts, insbesondere

\footnotetext{
${ }^{39}$ Woitschová ging bei ihrem Projekt von der traditionellen Vorstellung aus, dass die Urteilsmanuale des Appellationsgerichts eine wichtige Quelle zur Geschichte der Halsgerichtsbarkeit, der Kriminalität und anderer damit zusammenhängender, vor allem historisch-anthropologischer Phänomene darstellen, was wenigstens für das erste Jahrhundert der Existenz des Appellationsgerichts nicht zutrifft (WOITSCHOVÁ, Ortelní manuály 546, 552, 555f.).

${ }^{40}$ Dieser Tatsache war sich Woitschová bis zu einem gewissen Grad bewusst, wenn sie ausführt, dass , „[...] das Ziel des Forschungsprojekts in erster Linie ist [...], Unterlagen für die weitere Forschung bereitzustellen“ (ebd. 558).

${ }^{41}$ KřEePELKOVÁ, Apelační soud.

42 Ebd. 4.
}

die tschechische und deutsche Reihe der Urteilsbücher aus den Jahren 1548-1783, an das ehemalige Archiv des Landes Böhmen (Archiv Země české) abgegeben. ${ }^{43}$ Einige Bücher des Appellationsgerichts haben sich in der Handschriftensammlung des Archivs des Nationalmuseums ${ }^{44}$ und in der Sammlung der Bücher amtlicher Provenienz des Zentralen Staatsarchivs in Prag erhalten. ${ }^{45}$ Hingegen wurde in der zweiten Hälfte des 19. Jahrhunderts fast das gesamte in der Gerichtsregistratur befindliche Aktenmaterial vernichtet. Es hat sich nur ein kleiner Rest erhalten, der ca. fünf laufende (Regal-)Meter ausmacht. ${ }^{46}$ Dieser Rest wurde an das frühere Zentralarchiv des Innenministeriums abgegeben. ${ }^{47}$ Durch die Zusammenführung und Ordnung der genannten Bücherensembles und des Aktenmaterials wurde Anfang der 1960er Jahre im damaligen Zentralen Staatsarchiv der Archivfonds "Appellationsgericht 1548-1783“ gebildet, der anschließend in der ersten Hälfte der 1960er Jahre von der Archivarin und Historikerin Anita Křepelková inventarisiert wurde. Der Gesamtumfang des Fonds „Appellationsgericht 1548-1783 (1809)“ beträgt 25 laufende (Re-

${ }^{43}$ Ebd. Das Archiv des Landes Böhmen (ursprünglich Landesarchiv des Königreichs Böhmen/Zemský archiv Království českého) wurde 1862 eingerichtet und existierte bis zum Jahre 1954, als durch Zusammenlegung dieses Archivs und des Zentralarchivs des Innenministeriums das Zentrale Staatsarchiv in Prag entstand. Dazu PAZDEROVÁ, Státní ústřední archiv I/1, 39-51. Zum 1. Januar 2005 wurde das Zentrale Staatsarchiv in Nationalarchiv umbenannt.

${ }^{44}$ KřEepelKová, Apelační soud 4.

${ }^{45}$ Ebd.; PAZDEROVÁ, Státní ústřední archiv I/2, 166169.

46 KŘEPELKOVÁ, Apelační soud 4; PLECHÁČEK, Apelační soud 2.

${ }^{47}$ KŘEPELKOVÁ, Apelační soud 4. Das Zentralarchiv des Innenministeriums (vorher Archiv des Innenministeriums, bis 1919 Archiv der k.u.k. Statthalterei) bestand bis zum Jahre 1954, als durch Zusammenlegung dieses Archivs und des Archivs des Landes Böhmen das Zentrale Staatsarchiv in Prag eingerichtet wurde, PAZDEROVÁ, Státní ústřední archiv I/1, 21-38. 
gal-)Meter. Er besteht aus 328 Büchern und 40 Kartons Aktenmaterial. ${ }^{48}$

Unter den 328 Gerichts- und Amtsbüchern des Appellationsgerichts lassen sich acht bzw. neun Typen unterscheiden: ${ }^{49}$ 1. Sitzungsprotokolle (Verhandlungsprotokolle) aus den Jahren 16721783;50 2. "Parere“ (Gutachtenbücher) 15871734; ${ }^{51}$ 3. Kommission des Appellationsgerichts 1751-1783;52 4. Taxen 1612-1644;53 5. Verschiedene Amtsbücher $1534[!]-1783 ; 54$ 6. Instruktionen 1662-1703;55 7. Reskripte 1691-1787 [!];56 8. Urteilsbücher: A. Tschechische Reihe (Bücher mit Reinschriften der Urteile und sog. ortelní manuály/Urteilsmanuale) 1548-1783;57 B. Deutsche Reihe (Bücher mit Reinschriften der Urteile und sog. Protokollbücher) 1548-1780;58 C. Buch der Äußerungen des Appellationsgerichts in Sachen Wechsel und Handel 1778-1785;59 9. verschiedene Handschriften vorwiegend aus dem 18. Jahrhundert ${ }^{60}$ (Titular, ${ }^{61}$ Patentbücher, ${ }^{62}$ Normalienbücher, ${ }^{63}$ Indices ${ }^{64}$ etc.).

Das erhaltene Aktenmaterial stellt nur ein Bruchstück der einstigen Registratur des Appellationsgerichts bis zum Jahre 1783 dar. Relativ zusammenhängend erhalten haben sich nur Patente, Dekrete und Normalien, kaiserliche Reskripte zu den verhandelten Streitigkeiten

\footnotetext{
${ }^{48}$ KřEPELKOVÁ, Apelační soud 4.

${ }^{49}$ Detaillierte Klassifizierung der Gerichts- und Amtsbücher des Appellationsgerichts bei FRANCEK, ŠIMEK, Hrdelní soudnictví 77f.

${ }^{50}$ NA AS, Inv.-Nr. 1-37.

${ }^{51}$ Ebd. Inv.-Nr. 38, 39, 40a, 40b, 41-43.

52 Ebd. Inv.-Nr. 44-47.

${ }^{53}$ Ebd. Inv.-Nr. 48-56.

${ }^{54}$ Ebd. Inv.-Nr. 57-73.

55 Ebd. Inv.-Nr. 74a, 74b, 75, 76.

${ }^{56}$ Ebd. Inv.-Nr. 77-95.

${ }^{57}$ Ebd. Inv.-Nr. 96-183.

${ }^{58}$ Ebd. Inv.-Nr. 184-286.

${ }^{59}$ Ebd. Inv.-Nr. 287.

${ }^{60}$ Ebd. Inv.-Nr. 330-360.

${ }^{61}$ Ebd. Inv.-Nr. 335.

62 Ebd. Inv.-Nr. 341-344.

${ }^{63}$ Ebd. Inv.-Nr. 347-349.

${ }^{64}$ Ebd. Inv.-Nr. 357-360.
}

und einige aus dem 18. Jahrhundert stammende Taxordnungen. ${ }^{65}$ Der größte Teil des Aktenmaterials stammt erst aus der Zeit nach 1650.66

Für die Erforschung der Geschichte der Gerichtsbarkeit in Böhmen und in anderen Ländern der Böhmischen Krone und die Beschäftigung mit der Rechtsgeschichte Böhmens in der Frühen Neuzeit von größter und erstrangiger Bedeutung sind eindeutig die tschechische und die deutsche Reihe der Urteilsbücher des Appellationsgerichts, d.h. die Bücher mit Reinschriften der Urteile ${ }^{67}$ und die sog. Urteilsmanuale ${ }^{68}$ bzw. Protokollbücher. ${ }^{69}$ Dies betrifft vor allem die städtische Gerichtsbarkeit, und zwar sowohl die Zivil- als auch die Strafgerichtsbarkeit. Die insgesamt 191 Urteilsbücher bilden die Mehrheit der erhaltenen Bücher des Prager Appellationsgerichts. Von den Büchern mit Urteilsreinschriften haben sich in der tschechischen Reihe nur vier erhalten. ${ }^{70}$ Sie stammen aus den Jahren 1548-1564/66 und sind nach einzelnen Kreisen gegliedert. Ihre Eintragungen beinhalten das vorinstanzliche (d.h. meist durch ein städtisches Gericht gesprochene) Urteil, gegen das Berufung eingelegt worden war. Es folgt das Urteil des Appellationsgerichts, durch das das vorinstanzliche Urteil entweder bestätigt oder abgeändert

\footnotetext{
${ }^{65}$ Ǩ̌EPELKOVÁ, Apelační soud 4f.; PAZDEROVÁ, Státní ústřední archiv I/2,167f.

${ }^{66}$ Vgl. PLECHÁČEK, Apelační soud 2. Eine markantere Ausnahme stellen einige Patente, Dekrete und kaiserliche Reskripte (NA AS, Inv.-Nr. 288, 290), ferner einige Dutzend verschiedene Originalurkunden (ebd. Inv.-Nr. 292) und Akten einzelner Rechtsstreitigkeiten bis zum Jahre 1620 (ebd. Inv.-Nr. 298-306, 309, 310) dar.

67 PLECHÁČEK, Apelační soud 88, verwendet für die in Tschechisch geschriebenen Reinschriftbücher (NA AS, Inv.-Nr. 96-99) die Bezeichnung Präsidentenregister. Seiner Auffassung nach sei nach dem Jahre 1566 von der Führung dieser Bücher abgesehen worden und seien fernerhin nur Urteilsmanuale geführt worden. ${ }^{68}$ Siehe Anm. 57, 58. Vgl. auch KREUZ, Několik poznámek, insbes. $134 \mathrm{f}$.

${ }^{69}$ WoITSCHOVÁ, Ortelní manuály 551.

${ }^{70}$ NA AS, Inv.-Nr. 96-99.
} 
(ggf. ergänzt) wurde. Eine Abänderung des ursprünglichen Richterspruches wird gewöhnlich von einer mehr oder weniger umfangreichen Begründung begleitet. ${ }^{71}$ In der deutschen Reihe der Urteilsbücher des Appellationsgerichts sind insgesamt sechs Bücher mit Urteilsreinschriften auf uns gekommen.72 Es handelt sich hierbei um fünf chronologisch geordnete Bücher, die Urteile und Rechtsbelehrungen aus den Jahren 1548-1570 enthalten, die für Schlesien, die Lausitzen und einige Städte in Böhmen bestimmt waren. ${ }^{73}$ Dazu kommt noch ein Buch ähnlichen Inhalts, das die Zeitspanne von 15491587 umfasst. $^{74}$

Den Inhalt der sogenannten Urteilsmanuale (in der deutschen Reihe überwiegend als Protokollbücher ${ }^{75}$ bezeichnet) des Appellationsgerichts bilden in der Regel relativ kurze, flüchtig geschriebene Eintragungen, die mit einer Reihe von Änderungen, Einschüben, Streichungen sowie Kanzlei- und Expeditionsvermerken versehen sind. Die Eintragungen in den Urteilsmanualen sind ihrem Charakter nach Konzepte und haben offenbar ursprünglich als solche gedient. Folglich kann man die Urteilsmanuale (bzw. Protokollbücher) als Konzeptregister bezeichnen. Die Eintragungen enthalten gewöhnlich nur die Namen (oder Bezeichnungen) der streitenden Parteien, eine kurze, durchweg nur wenige Worte umfassende Charakterisierung des Streitgegenstandes, das Datum des vorinstanzlichen Urteils, gegen das Berufung eingelegt worden war, und die Bestätigung oder Abänderung (ggf. Ergänzung) des ursprünglichen Urteils; eine Abänderung wird von einer mehr oder weniger umfangreichen Begründung be-

\footnotetext{
${ }^{71}$ KREUZ, Několik poznámek 134.

${ }^{72}$ NA AS, Inv.-Nr. 281-286.

${ }^{73}$ Ebd. Inv.-Nr. 281-285.

${ }^{74}$ Ebd. Inv.-Nr. 286.

${ }^{75}$ Diese angemessenere Bezeichnung, die auf dem originalen deutschen Titel dieser Bücher basiert, verwendet konsequent WOITSCHOVÁ, Ortelní manuály, passim.
}

gleitet. Die Eintragungen in den Urteilsmanualen enthalten also nicht den Text des vorinstanzlichen Urteils. ${ }^{76}$ Die tschechische Reihe der Urteilsmanuale ist für die gesamte Zeit des Bestehens des Gerichts, also für die Jahre 1548-1783, fast ununterbrochen erhalten; 77 es handelt sich um 81 Bände. ${ }^{78}$ Auch die deutsche Reihe der Urteilsmanuale (sog. Protokollbücher) hat sich in fast ununterbrochener Folge erhalten. ${ }^{79}$ Die aus den Jahren 1550-1780 stammende Reihe besteht aus insgesamt 97 Bänden. ${ }^{80}$ Die tschechische Reihe der Urteilsbücher wurde vorwiegend in tschechischer Sprache geführt; erst in den letzten Jahrzehnten beginnt das Deutsche die Oberhand zu gewinnen. Die Urteilsbücher (Protokollbücher) der deutschen Reihe wurden ausschließlich in deutscher Sprache geführt. ${ }^{81}$

Einige der erhaltenen Urteilsbücher des Appellationsgerichts sind recht umfangreich und enthalten Tausende von Eintragungen. In vielen Jahrgängen der tschechischen Reihe der Urteilsmanuale aus dem halben Jahrhundert vor der Schlacht am Weißen Berg finden sich bis zu fünfhundert Eintragungen. (Die tschechische Reihe der Urteilsbücher aus der Zeit vor 1620 enthält fast ausschließlich Entscheidungen in Berufungen gegen Urteile der städtischen bzw. anderer Gerichte auf dem Gebiet des König-

\footnotetext{
${ }^{76}$ KREUZ, Několik poznámek 134f.

${ }^{77}$ Größere Lücken bestehen nur für die Jahre 1564 1567 und 1648-1657.

${ }^{78}$ NA AS, Inv.-Nr. 102-182. Weder zu den Reinschriftbüchern noch zu den Urteilsmanualen gehört eine Handschrift mit dem Titel „Buch der rechtlichen Begründungen von Gnadengesuchen, [...] die an den Kaiser gerichtet werden“ („Kniha právních zdůvodnění žádostí o milost [...] vznášených k císaři") (ebd. Inv.Nr. 183) aus den Jahren 1714-1715 (vgl. KŘEPELKOVÁ, Apelační soud 34) sowie zwei Bücher mit Musterentscheidungen aus der Zeit vor der Schlacht am Weißen Berg (NA AS, Inv.-Nr. 100, 101).

${ }^{79}$ Eine größere zeitliche Lücke besteht nur für die Jahre 1619-1621.

${ }^{80}$ NA AS, Inv.-Nr. 184-280.

${ }^{81}$ KřEPELKOVÁ, Apelační soud 4f.
} 
reichs Böhmen.) Die Anzahl der nur in der tschechischen Reihe der Urteilsbücher des Appellationsgerichts für die Zeit vor der Schlacht am Weißen Berg erfassten Urteile dürfte sich auf etwa 20.000 bis 25.000 belaufen. Die Gesamtzahl der Urteile und Entscheidungen, die in allen erhaltenen Urteilsbüchern des Prager Appellationsgerichts aus den Jahren 1548-1783 (d.h. sowohl der tschechischen als auch der deutschen Reihe) dokumentiert sind, lässt sich auf zwischen 60.000 und mehr als 100.000 veranschlagen. Vor diesem Hintergrund ist es kein Wunder, dass seit einigen Jahrzehnten, und zwar insbesondere von Forscherinnen und Forschern, die sich mit der Geschichte der städtischen Straf- und Halsgerichtsbarkeit und der Geschichte der Kriminalität beschäftigen, immer wieder mehr oder weniger konkrete Vorschläge gemacht wurden, die Urteilsbücher des Appellationsgerichts $\mathrm{zu}$ edieren bzw. zugänglich $\mathrm{zu}$ machen. ${ }^{82}$

\section{Die Entwicklung des Appellationsgerichts in Prag in den Jahren 1548-1783}

Das Appellationsgericht (Rat für Appellationen) in Prag wurde vom König von Böhmen Ferdinand I. durch eine am 20. Januar 1548 in Augsburg erlassene Instruktion, die an den böhmischen Hofmarschall Ladislav (Ladislaus) II. Popel von Lobkowitz und 13 weitere Personen adressiert wurde, errichtet. Darin wurden alle Adressaten zu Räten des neuen Gerichtshofes ernannt. ${ }^{83}$ Neben Ladislav II. von Lobkowitz, der zum Präsidenten des Gerichts bestellt wur-

\footnotetext{
${ }^{82}$ Dazu KREUZ, Stav a perspektivy 234-240; WOITSCHOVÁ, Ortelní manuály 550-558; dies., Edice 243251.

83 SNĚMY 2, 545-548. Siehe auch ZDENĚK, Dějiny král. Apellačního soudu 8-13. Deutsche Fassung der Instruktion bei SCHMIDT, Monographie 41-46.
}

de ${ }^{84}$ wurden drei weitere Angehörige des Herrenstandes, zwei Angehörige des Ritterstandes, vier Doktoren der Rechte und drei Vertreter der Städte zu Appellationsräten ernannt. ${ }^{85}$

Die Errichtung des Appellationsgerichts gehört zu den von Ferdinand I. kurz nach der Niederlage der aufständischen böhmischen Stände 1547 getroffenen Maßnahmen.86 Dadurch sollte vor allem der städtische Stand getroffen werden, der aktiv Anteil an dem ständischen Aufstand genommen hatte und nach dessen Niederschlagung (im Vergleich zum Herren- und Ritterstand) zum Objekt der schwersten Sanktionen wurde. ${ }^{87}$ Ihr Ziel war vor allem die Beschneidung der politischen Macht der böhmischen königlichen Städte, eine markante Schwächung ihres Eigentums und wirtschaftlichen Potentials und die Gewinnung der Kontrolle über ihre Selbstverwaltung und ihr Gerichtswesen. Zum Hauptinstrument der königlichen Kontrolle über das städtische Gerichtswesen sollte gerade das neu errichtete Prager Appellationsgericht werden.

Das Appellationsgericht ${ }^{88}$ wurde als eine ausschließlich herrscherliche (also nicht ständische) Gerichtsinstitution gegründet. Zum Gerichtssitz bestimmte Ferdinand I. die Prager Burg. Laut der Instruktion vom Januar 1548, in der in groben Zügen die Befugnisse und leitenden Prinzipien der Tätigkeit der neu errichteten Gerichtsinstitution festgelegt wurden, sollte in Zukunft

${ }^{84}$ SNĚMY 2, 545. Zur Person des ersten Präsidenten des Appellationsgerichts RYANTOVÁ, Ladislav II.

${ }^{85}$ Dazu bisher meist ausführlich PLECHÁČEK, Apelační soud 16; HaUSEnBlasová, Počátky 11, $14 \mathrm{f}$.

86 Zusammenfassung des aktuellen Forschungsstands zum ständischen Aufstand im Jahre 1547 im Sammelband VOREL, Stavovský odboj.

${ }^{87}$ ADAMOVÁ, Apelační soud 101.

${ }^{88}$ In der Gründungsinstruktion wird das Gericht als "př́isežné rady naše vkrálovstuie našem Českém k apelacím“ (SNĚMY 2, 545) bzw. „Unsere Geschworne Räthe in Unserem Königreich Böheimb [...] über den Appellationssachen" (SCHMIDT, Monographie 41) bezeichnet. 
jeder, der sich durch ein Urteil eines Gerichts einer königlichen Stadt beschwert fühlte, ausschließlich vor dem Prager Appellationsgericht Berufung einlegen, nicht vor den Gerichten in den Prager Städten, in Magdeburg, Leipzig oder vor einem anderen ausländischen Gericht. ${ }^{89}$ Darüber hinaus wies der Herrscher die städtischen Gerichte im Königreich Böhmen an, sich künftig mit Gesuchen um Rechtsbelehrung nicht an die genannten Gerichte zu wenden; diese Gesuche sollten in Zukunft ausschließlich an das Prager Appellationsgericht adressiert werden. ${ }^{90}$ Außerdem verbot er den Gerichten in der Markgrafschaft Mähren, in den schlesischen Fürstentümern und in den Markgrafschaften Ober- und Niederlausitz, d.h. in den Nebenländern der Böhmischen Krone, sich mit Bitten um Rechtsbelehrung an ein städtisches Gericht oder an eine Universität zu wenden. ${ }^{91}$

Das Prager Appellationsgericht war von Beginn an eine ständige Institution von wesentlich bürokratischem Charakter. Laut seiner Gründungsinstruktion sollte das Gericht das ganze Jahr über täglich tagen, mit Ausnahme von Mittwoch, Samstag, Sonntag und der bedeutenden Feste. ${ }^{92}$

Die territoriale Zuständigkeit des Appellationsgerichts wurde ebenfalls in der Gründungsinstruktion abgesteckt. Nach ihr sollten Einsprüche gegen Urteile der Gerichte aller königlichen Städte im Königreich Böhmen, in der Markgrafschaft Mähren, in den schlesischen Fürstentümern und in den Markgrafschaften Ober- und Niederlausitz vor dem Appellationsgericht eingelegt werden. Das Appellationsgericht wurde so $\mathrm{zu}$ einer der wenigen Institutionen, deren Wirkungskreis sich auf alle Länder der Böhmi-

\footnotetext{
89 SNĚMY 2, 545-548.

${ }^{90}$ Ebd. 545.

${ }^{91}$ Ebd. Vgl. auch SCHMIDT, Monographie 42 („,an keinen Schöppenstul weder universitet").

${ }^{2}$ SNĚMY 2, $545 f$.
}

schen Krone erstreckte. ${ }^{93}$ Die derart umrissenen Befugnisse gelang es dem Appellationsgericht relativ früh aber nur im Königreich Böhmen und in den beiden Lausitzen durchzusetzen. Die Lausitzer Markgrafschaften gehörten allerdings nur bis zu ihrer Besetzung durch das Heer des Kurfürsten von Sachsen Anfang der 1620er Jahre in den Wirkungskreis des Appellationsgerichts; 1635 wurden sie an Sachsen abgetreten. Im politisch und territorial zersplitterten Schlesien gestalteten sich Einfluss und Akzeptanz des Appellationsgerichts unterschiedlich. In den Mediatfürstentümern, in denen sich die Fürsten um die Erhaltung ihrer privilegierten Stellung im Bereich des Gerichtswesens bemühten, hat sich der Einfluss des Prager Appellationsgerichts kaum bemerkbar gemacht. In den unmittelbaren (Immediat-)Fürstentümern gewann das Appellationsgericht dagegen erheblich an Einfluss. ${ }^{94}$ Eine markante Ausnahme unter diesen unmittelbaren (Immediat-)Fürstentümern stellt allerdings das Fürstentum Opava/Troppau dar. Die Troppauer Stände lehnten es anfänglich kategorisch ab, die Kompetenz des Prager Appellationsgerichts anzuerkennen, wobei sie zur Begründung darauf verwiesen, dass sie sich mit ihren Gesuchen um Rechtsbelehrung an das Mährische Landesgericht wendeten. ${ }^{95}$ (Nach dem Abschluss des Breslauer Friedens im Juni 1742 büßte das Appellationsgericht seine $\mathrm{Zu}$ ständigkeit für den größten Teil Schlesiens ein. ${ }^{96}$ ) Nur in einem sehr bescheidenen Maße konnte sich das Appellationsgericht in Mähren durchsetzen. ${ }^{97}$ Der Wirkungskreis des Appella-

\footnotetext{
93 PLECHÁČEK, Apelační soud 30f.

94 Ebd. 34.

${ }^{95}$ Ebd. 38.

96 ŠALAK, Apelační soud 28.

97 PLECHÁČEK, Apelační soud 34f. In der gesamten Epoche vor der Schlacht am Weißen Berg sind Berufungen aus den mährischen (nicht nur königlichen) Städten in der tschechischen Reihe der Urteilsmanuale des Appellationsgerichts nur ganz ausnahmsweise und sporadisch verzeichnet.
} 
tionsgerichts erstreckte sich auch auf die Stadt Eger. 98

Erst in der Zeit nach der Schlacht am Weißen Berg, d.h. nach 1620, gelang es dem Appellationsgericht schrittweise, seine Befugnisse auf dem ganzen Gebiet der Böhmischen Krone geltend zu machen (allerdings mit Ausnahme der inzwischen abgetrennten Lausitzen). ${ }^{99}$ Diese Entwicklung wurde im Wesentlichen mit dem Erlass einer neuen Instruktion für das Prager Appellationsgericht durch Kaiser Ferdinand III. am 26. November 1644 zum Abschluss gebracht. ${ }^{100}$ In dieser Instruktion ordnete der Herrscher den mährischen königlichen Städten gegenüber an, sich hinsichtlich des Prager Appellationsgerichts nach denselben Regeln $\mathrm{zu}$ richten wie die böhmischen Städte. Aus Schlesien sollten laut der Instruktion Berufungen an das Appellationsgericht in Prag nicht nur aus den Städten, sondern (bis auf festgesetzte Ausnahmen) auch von den höheren Gerichten aller Fürstentümer gerichtet werden. ${ }^{101}$

Die Kompetenz des Appellationsgerichts im Hinblick auf Personen wurde in der Gründungsinstruktion nicht genau festgelegt. Dieser $\mathrm{Zu}-$ stand dauerte im Wesentlichen während des ersten Jahrhunderts des Bestehens des Gerichts an. ${ }^{102}$ In der Instruktion werden die Gerichte der patrimonialen Städte sowie die städtischen Untergerichte nicht erwähnt. ${ }^{103}$ In der Praxis war das Appellationsgericht für alle Bürger und

\footnotetext{
${ }^{98}$ PeterKa, Rechtsgeschichte 83; HaUsenblasová, Počátky 10. Die Unterordnung der (ehemaligen) Reichsstadt Eger wurde durch ein Hofdekret vom 27. August 1725 bekräftigt (ŠALAK, Apelační soud 28). 99 PLECHÁČEK, Apelační soud 38f.

${ }^{100}$ Ediert von SCHMIDT, Monographie 55-82. Vgl. auch PLECHÁČEK, Apelační soud 38f. Diese Instruktion wird manchmal nach ihrem Ausstellungsort als Linzer Instruktion bezeichnet (ŠALAK, Apelační soud, pas$\operatorname{sim})$.

101 PLECHÁČEK, Apelační soud 38f.

102 Ebd. 39-43.

${ }^{103}$ Ebd. 39.
}

Stadtbewohner sowie die Angehörigen der höheren Stände, sofern städtisches Eigentum betroffen war, zuständig. Das Appellationsgericht entschied auch in einigen Fällen, in denen die untertänige Landbevölkerung auftrat. ${ }^{104}$ Auf dem im September 1575 abgehaltenen Landtag gelang es, einen Beschluss durchzusetzen, nach welchem das Appellationsgericht in Zukunft nicht berechtigt sein sollte, in Angelegenheiten des Adels (also des Herren- und Ritterstandes) zu urteilen, und nur Berufungen gegen Urteile der städtischen Gerichte bei ihm eingelegt werden konnten. ${ }^{105}$ Aus den Lausitzen dagegen wurden während der gesamten Epoche vor der Schlacht am Weißen Berg Berufungen in Streitigkeiten zwischen Angehörigen des Herrenund Ritterstandes an das Appellationsgericht gerichtet, wobei über diese Einsprüche aufgrund einer Bewilligung König Ferdinands I. vom April 1549 auch dem Bürgerstand angehörige Räte befinden konnten. ${ }^{106}$

Was die sachliche Kompetenz anbelangt, konnte das Appellationsgericht im Prinzip über Berufungen in allen vor städtischen Gerichten verhandelten Fällen befinden. In der Praxis aber wurden an das Appellationsgericht in der Zeit vor der Schlacht am Weißen Berg und einige Dezennien nachher fast ausschließlich Berufungen in im Akkusationsverfahren (also nicht im Inquisitionsverfahren) verhandelten Prozessen gerichtet. ${ }^{107}$ Vom materiellrechtlichen Standpunkt aus gesehen überwiegen deshalb im ersten Jahrhundert des Bestehens des Appellationsgerichts bis in das zweite Drittel des 17. Jahrhunderts hinein deutlich Berufungen in zivilrechtlichen Fällen, insbesondere in Eigen-

\footnotetext{
${ }^{104}$ Ebd. 40.

105 SNĚMY 4, 271f.

106 PLECHÁČEK, Apelační soud 42f.

107 KREUZ, Několik poznámek 123-130, 134f.; DERS., K charakteristice procesního, insbes. 75-83; RŮŽIČKOVÁ, SIGLOVÁ, Apelační soud a odvolání 17.
} 
tums-, Schuld- und Erbschaftstreitigkeiten.108 Die strafrechtlichen Fälle stellen eindeutig eine Minderheit dar, wobei es meist um weniger schwerwiegende Delikte ging, die aufgrund einer privaten Klage verhandelt wurden. Gewichtigere Straftaten und Kriminaldelikte, die von den städtischen Gerichten gewöhnlich im Inquisitionsverfahren verhandelt wurden, kommen in der fraglichen Zeit vor dem Prager Appellationsgericht nur ganz sporadisch vor. ${ }^{109} \mathrm{Zu}$ einer beträchtlichen Erweiterung der Befugnisse des Appellationsgerichts kam es in der Zeit nach der Schlacht am Weißen Berg. ${ }^{110}$

Im Jahre 1571 erließ Kaiser Maximilian II. ein Mandat, dessen Absicht es war, die Zahl der Berufungen gegen Urteile des Appellationsgerichts an den König zu verringern. Künftig sollte jeder, der Revision beim König gegen ein vom Appellationsgericht verkündetes Urteil eingelegt hatte und dessen Gesuch als unbegründet abgewiesen wurde, eine Buße in Höhe von einem Fünftel des fraglichen Streitwerts bezahlen. Die Entscheidung über berechtigte Bitten um Revision übertrug der Herrscher dem Kammergericht des Königreichs Böhmen. ${ }^{111}$

Im Jahre 1580 erklärte das Appellationsgericht die erste böhmische Kodifikation des Stadtrechts, Koldíns Práva městská Království českého (Stadtrechte des Königreichs Böhmen) von 1579, zur für die Praxis verbindlichen Rechtsgrundlage. ${ }^{112}$ Es war auch Koldíns Gesetzbuch, das im Abschnitt "De appellationibus seu provocationibus - O odvolání aneb o appellacích“ („Von den Beru-

108 KREUZOVÁ, Agenda 54-56; RŮŽIČKOVÁ, SIGLOVÁ, Apelační soud a odvolání 34-43.

109 Vgl. Anm. 1077. Vgl. auch KreuZOVÁ, Agenda 34-

52; ČADOVÁ, Soudnictví 60-77; RŮŽIČKOVÁ, SIGLOVÁ, Apelační soud a odvolání 32-34.

110 PLECHÁČEK, Apelační soud 44.

111 Ebd. 46f.; AdAMOVÁ, Apelační soud 108f.; HAUSENBLASOVÁ, Počátky 9.

112 MALÝ, Dějiny českého a československého práva 91; PLECHÁČEK, Apelační soud 20; ADAMOVÁ, Apelační soud 111. fungen oder Appellationen“) erstmals die Berufung gegen Urteile der städtischen Gerichte detailliert regelte. ${ }^{113}$

Die Zahl der Räte des Appellationsgerichts betrug zunächst 14 (einschließlich des Präsidenten). ${ }^{114}$ Durch ein Reskript vom November $1628^{115}$ erhöhte Kaiser Ferdinand II. die Zahl der Räte auf 16 (außer dem Präsidenten). ${ }^{116}$ Acht unter ihnen sollten dem Herren- und Ritterstand angehören, weitere acht sollten Doktoren der Rechte sein, unter ihnen stets zwei Vertreter der Prager Städte.117 Der Präsident des Appellationsgerichts wurde direkt vom Herrscher ausschließlich aus Angehörigen des Herrenstandes ernannt. ${ }^{118}$ In den Jahren 1548-1628 lösten sich im Amt des Präsidenten insgesamt neun Personen aus den bedeutendsten Herrenfamilien ab. ${ }^{119}$ In der Epoche vor der Schlacht am Weißen Berg zählte der Präsident des Appellationsgerichts nicht zu den höchsten Landesbeamten des Königreichs Böhmen; ${ }^{120}$ zu einem solchen wurde er erst im Jahre 1627 aufgrund der Verneuerten Landesordnung. ${ }^{121}$

Die Kanzlei des Appellationsgerichts bestand aus zwei Expeditionen, einer tschechischen und einer deutschen. An der Spitze jeder von ihnen stand ein Sekretär. Der ältere der beiden Sekretäre stand der gesamten Gerichtskanzlei vor. ${ }^{122}$ Die Amtssprachen des Appellationsgerichts waren Tschechisch und Deutsch, wobei die Sprache des verkündeten Urteils sich nach der

\footnotetext{
${ }^{113}$ JIREČEK, Codex juris bohemici 87-91 (Art. C.IVC.XIII).

114 Hausenblasová, Počátky 11.

115 SCHMIDT, Monographie 50-53.

116 Hausenblasová, Počátky 11; PlecháčEK, Apelační soud 62.

117 Ebd. 28, 62.

118 Ausführlich zur Stellung des Präsidenten des Appellationsgerichts in den Jahren 1548-1644 ebd. 57-61.

${ }^{119}$ Hausenblasová, Počátky 11.

120 PLECHÁČEK, Apelační soud 59.

${ }^{121}$ VLO, 44-47 (Art. A. XXXII).

122 PLECHÁČEK, Apelační soud 66f.
} 
Sprache des zugrundeliegenden Antrags richtete. ${ }^{123}$

Die Verneuerte Landesordnung für das Königreich Böhmen von 1627 brachte eine wesentliche Erweiterung der Kompetenzen des Appellationsgerichts. Gleichzeitig stellte sie die erste Regelung dar, in der das Prager Appellationsgericht eine gewisse verfassungsrechtliche Verankerung erfuhr, indem sein Präsident unter die höchsten Landesbeamten des Königreichs Böhmen aufgenommen wurde. ${ }^{24}$ Durch die Verneuerte Landesordnung erwarb das Appellationsgericht eindeutig auch umfassende Kompetenz im Bereich der Halsgerichtsbarkeit, einschließlich der Befugnis, alle von den städtischen (bzw. auch anderen) Gerichten in Böhmen gefällten Todesurteile (d.h. im Inquisitionsverfahren verkündete Urteile) zu bestätigen. ${ }^{125}$ Zur Revisionsinstanz für die böhmischen Gerichte mit landesweiter Zuständigkeit (einschließlich des Landesgerichts und des Prager Appellationsgerichts) wurde nach der Verneuerten Landesordnung die Böhmische Hofkanzlei.126

Das schon erwähnte Reskript Ferdinands II. von 1628 erhöhte auch die Anforderungen an die fachliche Qualifikation der Räte; künftig sollten graduierte Juristen die Hälfte des Gerichtskollegiums bilden. ${ }^{127}$

Eine bedeutsame und tiefgreifende Reform des Prager Appellationsgerichts brachte an der Neige des ersten Jahrhunderts seines Bestehens die von Kaiser Ferdinand III. in Linz in Form eines Reskripts am 26. November 1644 erlassene Instruktion. ${ }^{128}$ Diese umfassende Instruktion wurde zur Grundlage der Organisation des Appella-

\footnotetext{
${ }^{123}$ Ebd. 81.

124 S. oben Anm. 121.

${ }^{125}$ VLO, 500-503 (Art. R.VI-R.VIII), 508f. (Art. R.XVIII).

Vgl. auch PLECHÁČEK, Apelační soud 45f.

${ }^{126}$ VLO, 264f. (Art. F. LXXXII).

127 SCHMIDT, Monographie 51; PLECHÁČEK, Apelační soud 28.

128 SCHMIDT, Monographie 55-82.
}

tionsgerichts bis zum Jahre 1783. Die Instruktion legte die Pflichten des Präsidenten und der Räte des Gerichts genau fest. Ferner wurden die für seine Tätigkeit geltenden Verfahrensregeln detailliert beschrieben und sein territorialer Wirkungskreis präzisiert. ${ }^{129}$ Mit Hinweis auf die Verneuerte Landesordnung schrieb die Instruktion außerdem die Befugnisse des Appellationsgerichts auf dem Gebiet der Halsgerichtsbarkeit fest. 130

Durch das Reskript Ferdinands III. vom 18. Juni $1651^{131}$ wurde dem Prager Appellationsgericht die Hauptmannschaft der deutschen Lehen angegliedert; ihm wurden damit die Agenden der auswärtigen (deutschen) Lehen der Böhmischen Krone übertragen. ${ }^{132}$

Erst im letzten Viertel des 17. Jahrhunderts gelang es dem Appellationsgericht, seine umfangreichen Kompetenzen im Bereich der Halsgerichtsbarkeit einschließlich der Befugnis, die durch alle städtischen Gerichte in Böhmen gefällten Todesurteile zu bestätigen, in der Praxis durchzusetzen. Diese Befugnis war dem Prager Appellationsgericht zwar schon in der Verneuerten Landesordnung für das Königreich Böh-

\footnotetext{
${ }^{129}$ Ebd. 71, 73f.

${ }^{130}$ Ebd. 65 (Art. 16). Vgl. auch D'ElverT, Zur Oesterreichischen Verwaltungs-Geschichte 191; ŠALAK, Apelační soud 37. Siehe auch oben Anm. 125.

${ }^{131}$ SCHMIDT, Monographie 85-91.

132 Veselý, O přenesení působnosti. Vgl. auch ADAMOVÁ, Apelační soud 110f.; PLECHÁČEK, Apelační soud 95. Die Hauptmannschaft der deutschen Lehen als spezielles königliches Amt für die Verwaltung der auswärtigen Lehen der Böhmischen Krone ist seit den 1490er Jahren belegt. Die Appellationsräte beteiligten sich schon in der zweiten Hälfte des 16. Jahrhunderts an der Tätigkeit der Hauptmannschaft. Im Dreißigjährigen Krieg ging die Hauptmannschaft der deutschen Lehen unter und wurde nach seinem Ende nicht wieder errichtet. Ihre Agenden wurden aber an das Prager Appellationsgericht übertragen. Zur Geschichte der Hauptmannschaft der deutschen Lehen HAIMERL, Die deutsche Lehenhauptmannschaft; VESELÝ, O soudu hejtmanství německých lén; JANÁK, HLEDíKOVÁ, DOBEŠ, Dějiny správy 103, 124.
} 
men $^{133}$ übertragen worden, erst von dieser Zeit an bestätigte bzw. änderte das Appellationsgericht aber auch die Todesurteile (ggf. auch andere Urteile), die im Inquisitionsverfahren durch städtische (ggf. andere) Gerichte in Böhmen verkündet worden waren. ${ }^{134}$ Im letzten Viertel des 17. Jahrhunderts kann man also einen markanten Anstieg der Anzahl der Berufungen gegen die Urteile der städtischen Halsgerichte, ${ }^{135}$ eventuell auch der Gnadengesuche, beim Appellationsgericht verzeichnen. Diese Tatsache hängt mit der erwähnten Durchsetzung der Befugnisse des Appellationsgerichts zusammen, die schon in der Verneuerten Landesordnung und erneut in der Instruktion von 1644 verankert worden waren. Der plötzliche und rasche Anstieg der Anzahl der Berufungen gegen Urteile der städtischen Halsgerichte vor dem Appellationsgericht, der Anfang der 1680er Jahre zu beobachten ist, dürfte seine unmittelbare Ursache in dem Reskript Kaiser Leopolds I. vom 27. September 1677 haben, das es den Untertanen ermöglichte, binnen 14 Tagen vor dem Appellationsgericht Berufung gegen die Urteile der Patrimonialgerichte in Strafsachen einzulegen. Die Praxis, sich mit der Bitte um Rechtsbelehrung in allen gewichtigeren Kriminalfällen an das Appellationsgericht zu wenden, bürgerte sich demzufolge in Böhmen erst im letzten Viertel des 17. Jahrhunderts ein. Bis zu dieser Zeit verfuhren die Patrimonialgerichte und die Kriminalgerichte der patrimonialen Städte und Marktflecken mit Zustimmung der Obrigkeit oft selbstständig. ${ }^{136}$

Seit dem Ende des 17. Jahrhunderts erstarkte schrittweise auch die Kompetenz des Prager Appellationsgerichts bei der Kontrolle des umfassenden, in seiner Entwicklung stagnierenden und den Bedürfnissen des absolutistischen Staates immer weniger gerecht werdenden dezentra-

\footnotetext{
${ }_{133}$ Siehe Anm. 125.

134 Vgl. oben Anm. 20.

135 RŮŽIČKOVÁ, SigLOVÁ, Apelační soud a odvolání 17.

136 ŠALAK, Apelační soud 37.
}

lisierten Netzes von städtischen Halsgerichten in Böhmen. ${ }^{137}$

$\mathrm{Zu}$ einer wesentlichen Erweiterung der Befugnisse des Appellationsgerichts in Prag kam es durch den Erlass der Halsgerichtsordnung Kaiser Josephs I. (Josephina) im Juli 1707.138 Nach der Josephina sollte das Appellationsgericht u.a. auch über die Anwendung der Folter befinden. Allen Gerichten, die berechtigt waren, die Folter zu verhängen, wurde deshalb befohlen, sich künftig an keine Universität oder andere Gerichtsinstanz mehr zu wenden, sondern ausschließlich an das Prager Appellationsgericht. ${ }^{139}$ Das Appellationsgericht war laut Josephina auch berechtigt, eine im Inquisitions- und Akusationsverfahren ergangene widerrechtliche Entscheidung des untergeordneten Gerichts aufzuheben, die Sache neu $\mathrm{zu}$ verhandeln und die Verantwortlichen für die Fehlentscheidung $\mathrm{zu}$ bestrafen. ${ }^{140}$ Die Josephina regelte recht eingehend, wie Berufungen einzulegen und Gnadengesuche einzureichen waren. Sie erlaubte u.a. auch den Verurteilten oder ihren Anwälten, bis zum letzten Augenblick vor der Vollstreckung der Todesstrafe beim Appellationsgericht Berufung einzulegen oder ein Gesuch auf Begnadigung einzureichen. ${ }^{141}$

Durch zwei am 11. April 1709 und 11. Februar 1769 erlassene Reskripte wurden die Agenden des Appellationsgerichts um die Entscheidung in Fällen erweitert, in denen das Untergericht wegen fehlerhafter Rechtsprechung zu einer Entschädigung verurteilt wurde; das Appellationsgericht war dabei befugt, die Höhe des an

\footnotetext{
${ }^{137}$ RouČKA, Poznámky, insbes. 122-124. Vgl. auch KREUZ, Proměny; ŠALAK, Apelační soud 44-46.

138 Josephina.

${ }^{139}$ Josephina Art. XVI. Vgl. SCHMIDT, Monographie 23; PLECHÁČEK, Apelační soud 96.

${ }^{140}$ Josephina Art. III, § 4.

${ }^{141}$ Josephina Art. XXI.
} 
die geschädigte Partei zu leistenden Schadensersatzes zu bestimmen. ${ }^{142}$

Durch das Reskript Kaiserin Maria Theresias vom 18. November $1752^{143}$ wurde das Ober- und Appellationsgericht in Brünn errichtet, dessen Kompetenz sich auf das Gebiet von Mähren und des damals österreichischen Schlesien erstreckte. Die territoriale Zuständigkeit des Prager Appellationsgerichts wurde dadurch auf das Gebiet Böhmens beschränkt. ${ }^{144}$

Das Appellationsgericht in Prag beteiligte sich auch an der Vorbereitung der Reform der Halsgerichte in Böhmen, die nach einigen Dezennien erfolgloser Versuche und Vorbereitungen unter Maria Theresia durch die Verkündung der „Pragmatical-Sanction wegen Restringierung der Halsgerichte und Dotirung des fundi criminalis in Böhmen" am 15. Juli 1765 vollendet wurde. Dadurch wurde die Zahl der Halsgerichte in Böhmen von bisher mehr als 380 auf 29 bzw. 30 herabgesetzt. ${ }^{145}$ An den Gerichten, die weiterhin die Halsjurisdiktion ausübten, sollte künftig ein in den Rechtswissenschaften ausgebildeter Syndicus wirken, der vor Antritt seines Amtes eine Qualifikationsprüfung vor dem Appellationsgericht $\mathrm{zu}$ bestehen hatte. ${ }^{146}$

Mit der Halsgerichtsordnung Kaiserin Maria Theresias (Constitutio Criminalis Theresiana) ${ }^{147}$ für die habsburgischen Erbländer, die am 31. Dezember 1768 kundgemacht wurde und zum 1. Januar 1770 in Kraft trat, ${ }^{148}$ gewann das Appellationsgericht die Befugnis der ausschließlichen Entscheidung über die schwersten Kriminaldelikte, namentlich Majestätsbeleidigung,

\footnotetext{
142 SCHMIDT, Monographie 23.

143 Ebd. $96 f$.

${ }^{144}$ Ebd. 25; PLECHÁČEK, Apelační soud 96.

${ }^{145}$ Einen Neudruck der „Pragmatical-Sanction“ besorgte MAASBURG, Die Organisierung 93-116. Vgl. auch ROUČKA, Poznámky 124-128; KREUZ, Proměny. 146 SCHMIDT, Monographie 24f.; RoUČKA, Poznámky 128.

147 Constitutio Criminalis Theresiana.

${ }^{148}$ Vgl. ŠOlLE, Trestní soudnictví, insbes. 90.
}

Rebellion, öffentlicher Aufruhr, Verschwörung, Landesverrat, Störung des Landfriedens und weitere Taten, die das Land oder den Landesherrn in Gefahr brachten. ${ }^{149}$ Die niedrigeren Halsgerichte mussten bei folgenden Tatbeständen die Zustimmung des Appellationsgerichts zu ihren Urteilen einholen: Gotteslästerung, Ketzerei, Zauberei, Hexerei, Schatzgraben, teuflische bzw. dämonische Besessenheit, abergläubische Unternehmungen, Münzfälschung und -verderbung, Entführung, Anwerben von Soldaten für fremde Herrscher, von Rotten verübte Straßenräuberei und Mordbrennerei, Giftmischerei, gedungener Mord, Unkeuschheit wider die Natur, Duellieren und Delikte, die mit Landesverweisung bestraft wurden. ${ }^{150}$ Ferner lag es nach der Theresiana dem Appellationsgericht ob, in durch fremde Personen höheren Standes, d.h. nicht dem einheimischen Herren- oder Ritterstand angehörende Personen verübten Verbrechen $\mathrm{zu}$ verhandeln und sie $\mathrm{zu}$ ahnden. ${ }^{151}$

Das Appellationsgericht in Prag hörte auf in seiner ursprünglichen Gestalt zu bestehen infolge einer im Laufe der 1780er Jahre, also in der Zeit des Josephinismus, durchgeführten Reorganisation. Durch Hofdekret vom 12. April 1782, Nr. 44 der Justizgesetzsammlung, wurde das Prager Appellationsgericht zum Allgemeinen Appellationsgericht für Böhmen erklärt, indem angeordnet wurde, dass Berufungen gegen Urteile der Gerichte niederer Instanz in Böhmen dort eingelegt werden sollten. Tatsächlich kam es infolge dieses Dekrets aber zu keiner Änderung. Das bisherige Appellationsgericht in Prag und das Appellations-, Merkantil- und Wechselgericht beendeten ihre Tätigkeit erst auf der Grundlage des Hofdekrets vom 7. April 1783 (zum 31. Mai 1783). ${ }^{152}$ An ihrer Stelle wurde am

\footnotetext{
${ }^{149}$ CCTh Art. 21, § 4.

${ }^{150}$ CCTh Art. 21, § 5.

${ }_{151}$ CCTh Art. 22, § 10.

${ }^{152}$ Der Text dieses Hofdekrets wurde erneut gedruckt von SCHMIDT, Monographie 109-111.
} 
1. Juni 1783 das Allgemeine Appellationsgericht in Prag gegründet. ${ }^{153}$

Im Jahre 1787 wurde das Allgemeine Appellationsgericht in Prag im Rahmen einer umfassenden Reform der Strafgerichtsbarkeit, deren Grundsätze im Patent Josephs II. vom 20. August 1787 (Nr. 712 der Justizgesetzsammlung) festgelegt sind, zum Obersten Kriminalgericht für Böhmen. ${ }^{154}$ Diese Stellung hat es sich bis 1850 bewahrt, also über den Widerruf der josephinischen Reform der Straf- bzw. Kriminalgerichtsbarkeit im Jahre 1790 hinaus. ${ }^{155}$

\section{Schluss}

Das Appellationsgericht in Prag (1548-1783) stellt zweifelsohne eine bedeutende und von der bisherigen Forschung ungleichmäßig bearbeitete Gerichtsinstitution des frühneuzeitlichen böhmischen Staates dar. Die Urteilsbücher des Prager Appellationsgerichts enthalten bzw. dokumentieren Zehntausende von Urteilen, die dieses Gericht in den Jahren 1548-1783 fällte. Die Bücher des Appellationsgerichts sind daher ein bedeutendes und polyvalentes Quellencorpus nicht nur für die Geschichte des böhmischen Rechts und Gerichtswesens in der Frühen Neuzeit, sondern auch für die Stadtgeschichte, die Geschichte von Kriminalität und Devianz und viele andere Fragen, und zwar nicht nur in Böhmen, sondern auch (wenn auch nicht in glei-

153 ŠALAK, Apelační soud 56f.; PAZDEROVÁ, Státní ústřední archiv I/2, 169. Der umfangreiche Archivfonds Apelační a vrchní zemský soud \{Appellations- und Oberlandesgericht\} (1548) 1783-1850 (1904) wird gegenwärtig in der II. Abteilung des Nationalarchivs in Prag aufbewahrt. Der Fonds wurde im Jahre 1982 inventarisiert. Sein Gesamtumfang beträgt 463 Regalmeter; er besteht aus 1731 Büchern und 2953 Kartons Aktenmaterial. Dazu PAZDEROVÁ, Státní ústřední archiv I/2, 169-178; STUPKOVÁ, Apelační a vrchní zemský soud.

154 ŠolLE, Trestní soudnictví $105 f$.

${ }^{155}$ Ebd. 106f. chem Maße) in den Nebenländern der Böhmischen Krone, also in Mähren, Schlesien und in den Lausitzen.

Zweifellos wäre es sehr wünschenswert, die Bücher des Appellationsgerichts in geeigneter Form zu edieren bzw. zugänglich zu machen. Fraglich ist aber inzwischen, welches die geeignete Form einer solchen Erschließung dieses umfassenden Quellenensembles sein sollte.

\section{Korrespondenz:}

PhDr. Petr Kreuz, Dr. Hlavní město Praha Magistrát, Archiv Archivní 6, 14900 Praha 4, Tschechische Republik Petr.Kreuz@praha.eu

\section{Abkürzungen:}

Inv. Inventar

NA AS Národní archiv v Praze/Nationalarchiv Prag, fond Apelační soud/Fonds Appellationsgericht 1548-1783 (1809)

KUP Univerzita Karlova v Praze, Karlsuniversität Prag

PHS Právněhistorické studie

VLO Verneuerte Landesordnung für das Königreich Böhmen (Obnovené zř́zení zemské); Edition: JIREČEK, Obnovené

Siehe auch das allgemeine Abkürzungsverzeichnis: http://www.rechtsgeschichte.at/files/abk.pdf

\section{Literatur:}

Karolina ADAMOVÁ, Apelační soud v Českém království v letech 1548-1651 \{Das Appellationsgericht im Königreich Böhmen in den Jahren 1548-1651\}, in: Collectanea opusculorum ad iuris historiam spectantium Venceslao Vaněček septuagenario ab amicis discipulisque oblata. Pocta akademiku Václavu Vaněčkovi k 70. narozeninám \{Festschrift für Václav Vaněček zum 70. Geburtstag\} (Praha 1975) 101-112.

J[osef] Graf v. AUERSPERG, Geschichte des königlichen böhmischen Appellationsgerichtes, Teil 1-2 (Prag 1805). 
Bohumil BAXA, Dějiny práva na území Republiky československé \{Rechtsgeschichte auf dem Gebiet der Tschechoslowakischen Republik\} (Brno 1935).

Jiří L. BíLÝ, Právní dějiny na území České republiky \{Rechtsgeschichte auf dem Gebiet der Tschechischen Republik\} (Praha 2003).

Hana ČADOvÁ, Soudnictví města Český Brod ve světle ortelních manuálů apelačního soudu v době předbělohorské \{Die Gerichtsbarkeit der Stadt Český Brod im Zeitalter vor der Schlacht am WeiBen Berg im Lichte der Urteilsmanuale des Appellationsgerichts\} (Bakkalaureatsarb., Fakulta humanitních studií Univerzity Hradec Králové 2006).

Jaromír ČELAKOVSKÝ, Povšechné právní dějiny české \{Allgemeine böhmische Rechtsgeschichte\} (Praha 21900).

Constitutio Criminalis Theresiana oder der RömischKaiserl. Zu Hungarn und Böheim etc. etc. Königl. Apost. Majestät Mariä Theresiä, Erzherzogin zu Oesterreich etc. etc. Peinliche Gerichtsordnung (Wien 1769).

Christian D’ELVERT, Zur Oesterreichischen Verwaltungs-Geschichte mit besonderer Rücksicht auf die böhmischen Länder (Brünn 1880).

Jindřich FRANCEK (Hg.), Hrdelní soudnictví českých zemí v 16.-18. století. Sborník př́spěvků z konference konané v Pardubicích 21.-22. 9. 1995 \{Die Halsgerichtsbarkeit in den böhmischen Ländern im 16.-18. Jahrhundert. Sammelband der Beiträge der Konferenz in Pardubice am 21.22. September 1995\} (Pardubice 1996).

Jindřich FRANCEK, Zločin a trest v českých dějinách \{Verbrechen und Strafe in der böhmischen Geschichte\} (Praha 1999).

Jindřich FRANCEK, Tomáš ŠIMEK (Hgg.), Hrdelní soudnictví českých zemí. Soupis pramenů a literatury \{Die Halsgerichtsbarkeit in den böhmischen Ländern. Verzeichnis der Quellen und Literatur\} (Zámrsk-Pardubice 1995).

Franz HAIMERL, Die deutsche Lehenhauptmannschaft (Lehenschranne) in Böhmen. Ein Beitrag zur Geschichte des Lehenwesens in Böhmen mit urkundlichen Beilagen (Prag 1848).

Květoslava HAUBERTOVÁ, Loketsko v ortelních manuálech apelačního soudu $\mathrm{v}$ letech 1548-1740. K zániku chebské oblasti městského práva po roce 1548 \{Der Ellbogener Kreis in den Manualen zu den Urteilen des Appellationsgerichts in den Jahren 1548-1740. Die Einschränkung der Stadtrechte im Gebiet von Eger nach 1548\}, in: Sborník Chebského muzea (2005) 8-22.

Jaroslava HAUSENBLASOVÁ, Počátky apelačního soudu v Čechách a jeho personální obsazení \{Die Anfänge des Appellationsgerichts in Böhmen und seine personelle Besetzung\}, in: Paginae historiae 13 (2005) 5-31.

Michaela HruBÁ, Ludmila SulitKOVÁ, Vilém ZÁBRANSKÝ (Hgg.), Stav a perspektivy zpřístupňování středověkých a raně novověkých městských knih \{Stand und Perspektiven des Zugänglichmachens mittelalterlicher und frühneuzeitlicher Stadtbücher\} (= Ústecký sborník historický, Supplementum 1, Ústí nad Labem 2010).

Jan JANÁK, Zdeňka HLEDíKOVÁ, Dějiny správy v českých zemích do roku 1945 \{Verwaltungsgeschichte der böhmischen Länder bis 1945\} (Praha 1989).

Jan JANÁK, Zdeňka HledíkOvÁ, Jan DOBEš, Dějiny správy v českých zemích od počátků státu po současnost \{Verwaltungsgeschichte in den böhmischen Ländern von den Anfängen des Staates bis zur Gegenwart\} (Praha 2005).

Hermenegild JIREČEK (Hg.), Obnovené právo a zřízení zemské dědičného království Českého. Verneuerte Landes-Ordnung des Erb-Königreichs Böhmen 1627 (Praha 1888).

Josef JIREČEK (Hg.), Codex juris bohemici, Tomi IV pars III: Monumenta juris municipalis, Sectio II, exhibens Mag. Pauli Christiani a Koldín Jus municipale regni Bohemiae una cum compendio ejusdem juris (Pragae 1876).

Josephina: Der Römischen Kayser, auch zu Hungarn und Böhaimb etc. Königl. Mayestät Josephi Des Ersten, Ertz-Herzogens zu Oesterreich, Unsers Allergnädigsten Herrens, Neue Peinliche HalsGerichts-Ordnung vor das Königreich Böhaimb, Marggrafthumb Mähren und Herzogthumb Schlesien (Prag 1708).

Josef KALOUSEK, České státní právo \{Böhmisches Staatsrecht\} (Praha 21892).

Jan KAPRAS, Právní dějiny zemí Koruny české \{Rechtsgeschichte der Länder der Böhmischen Krone\}, Teil 2-3 (Praha 1913-1920).

DERS., Přehled právních dějin zemí České koruny \{Überblick über die Rechtsgeschichte der Länder der Böhmischen Krone\} (Praha ${ }^{5}$ 1935).

Jiří KLABOUCH, Staré české soudnictví (jak se dříve soudívalo) \{Das alte böhmische Gerichtswesen (wie man in früheren Zeiten Gericht hielt)\} (Praha 1967).

Anita Ǩ̌EPELKOVÁ, Apelační soud 1548-1783 (1788). Inventář \{Das Appellationsgericht 1548-1783 (1788). Inventar\} (Praha 1964).

Petr KReUZ, K charakteristice procesního projednávání trestních př́ipadů v českých městech doby předbělohorské \{Zur Charakteristik des Verfahrens in Strafsachen in den böhmischen Städten in 
der Zeit vor der Schlacht am Weißen Berg\}, in: FRANCEK, Hrdelní soudnictví 63-100.

DERS., Několik poznámek k otázce odrazu kriminality v písemnostech soudů předbělohorských Čech (Př́ispěvek k metodice studia sociálních dějin kriminality $\mathrm{v}$ českých zemích $\mathrm{v}$ raném novověku) \{Bemerkungen zum Niederschlag der Kriminalität im Schriftgut der Gerichte in Böhmen vor der Schlacht am Weißen Berg (Ein Beitrag zur Methodik der Sozialgeschichte der Kriminalität in den böhmischen Ländern in der Frühen Neuzeit)\}, in: DERS., Vojtěch ŠUsteK (Hgg.), Seminář a jeho hosté II. Sborník příspěvků k nedožitým 70. narozeninám doc. PhDr. Rostislava Nového \{Das Seminar und seine Gäste. Sammelband anlässlich des 70. Geburtstags des verstorbenen Doz. PhDr. Rostislav Nový\} (= Documenta Pragensia 23, Praha 2004) 123-161.

DERS., Proměny organizace trestního soudnictví v Čechách od tereziánských reforem do roku 1848 \{Die Änderungen in der Organisation der Strafgerichtsbarkeit in Böhmen seit den theresianischen Reformen bis zum Jahre 1848\}, in: Zločin a trest v české kultuře 19. století. Sborník prríspěvků z 30. ročníku sympozia k problematice 19. století. Plzeň, 25.-27. února 2010 \{Verbrechen und Strafe in der böhmischen Kultur im 19. Jahrhundert. Sammelband der Beiträge des 30. Symposions zur Problematik des 19. Jahrhunderts, Pilsen, 25.-27. Februar 2010\} (Praha 2011) 19-28.

DERS., Stav a perspektivy vydávání smolných knih a př́buzných pramenů $\mathrm{k}$ dějinám hrdelního soudnictví v českých zemích \{Stand und Perspektiven der Edition der Pechbücher und verwandter Quellen zur Geschichte der Halsgerichtsbarkeit in den böhmischen Ländern\}, in: HRUBÁ, SULITKOVÁ, ZÁBRANSKÝ, Stav a perspektivy 213-240. Deutsche Fassung in einem von Peter JOHANEK u.a. herausgegebenen Sammelband über mittelalterliche und frühneuzeitliche Stadtbücher (Münster 2013) (im Druck).

Lenka KREUZOVÁ, Agenda městského soudu v Poděbradech $v$ době předbělohorské ve světle knih čistopisů a ortelních manuálů apelačního soudu v Praze (1548-1618) \{Die Agenden des Stadtgerichts in Poděbrady im Zeitalter vor der Schlacht am Weißen Berg im Licht der Bücher mit Urteilsreinschriften und der Urteilsmanuale des Appellationsgerichts in Prag (1548-1618)\} (phil. Dipl.arb., KUP 2005).

Friedrich von MAASBURG, Die Organisierung der böhmischen Halsgerichte im Jahre 1765 (Prag 1884).
Karel MALÝ u.a., Dějiny českého a československého práva do roku 1945 \{Geschichte des tschechischen und tschechoslowakischen Rechts bis 1945\} (Praha 21999).

DERS., Florián SIVÁK, Dějiny státu a práva v Československu \{Staats- und Rechtsgeschichte in der Tschechoslowakei\}, Teil 1 (Praha 1988).

Michaela NeudertovÁ (= HrubÁ), Lenka KutHANOVÁ, Ke komunikaci apelačního soudu a městských hrdelních soudi̊ $\mathrm{v}$ době předbělohorské \{Zur Kommunikation zwischen dem Appellationsgericht und den städtischen Halsgerichten in der Zeit vor der Schlacht am Weißen Berg\}, in: FRANCEK, Hrdelní soudnictví 119-132.

Emil OTT, Beiträge zur Receptions-Geschichte des römisch-canonischen Processes in den böhmischen Ländern (Leipzig 1879).

Jaroslav PÁNEK, Die Halsgerichtsbarkeit der böhmischen Städte und Märkte vom 16. bis 18. Jahrhundert, in: MIÖG 96 (1988) 95-131.

Ders., Hrdelní soudnictví města Příbramě v 17 . a 18. století (Příspěvek k poznání pozdně feudálního hrdelního soudnictví v Čechách a $\mathrm{k}$ metodice studia jeho dějin) \{Die Halsgerichtsbarkeit der Stadt Př́bram im 17. und 18. Jahrhundert (Ein Beitrag zur spätfeudalen Halsgerichtsbarkeit in Böhmen und zur Methodik der Erforschung ihrer Geschichte)\}, in: Středočeský sborník historický 13 (1978) 87-195.

DERS., Městské hrdelní soudnictví v pozdně feudálních Čechách (Výsledky, problémy a perspektivy studia) (Die städtische Halsgerichtsbarkeit im spätfeudalen Böhmen (Ergebnisse, Probleme, Forschungsperspektiven)\}, in: Československý časopis historický 32 (1984) 693-728.

Alena PAZDerová u.a., Státní ústřední archiv v Praze. Průvodce po archivních fondech a sbírkách \{Zentrales Staatsarchiv in Prag. Ein Begleiter durch die Archivfonds und -sammlungen\}, Teil I, Bd. 1-2 (Praha 1997-2000).

Otto PETERKA, Rechtsgeschichte der böhmischen Länder in ihren Grundzügen dargestellt, Bd. 2 (Reichenberg 1928).

Ivo PleCHÁČEK, Apelační soud v Čechách do roku 1644 \{Das Appellationsgericht in Böhmen bis zum Jahr 1644\} (phil. Dipl.arbeit, KUP 1956).

Jaroslav PLESKOT, Apelační soud v letech 1548-1620. Vznik, pravomoc a činnost \{Das Appellationsgericht in den Jahren 1548-1620. Entstehung, Zuständigkeit und Tätigkeit\} (phil. Dipl.arbeit, KUP 2006).

Eva ProcházKovÁ, Perzekuce romských kočovníků v českých zemích v 18. století \{Die Verfolgung der Roma-Nomaden in den böhmischen Ländern im 
18. Jahrhundert\}, in: Sborník archivních prací 42 (1992) 307-409.

DIES., Současný stav výzkumu dějin kriminality a soudní praxe $\mathrm{v}$ éře dentralizovaného soudnictví \{Der zeitgenössische Stand der Forschungen zur Kriminalitätsgeschichte im Zeitalter der dezentralisierten Gerichtsbarkeit\}, in: Jiří PEŠEK (Hg.), VIII. sjezd českých historiků. Hradec Králové 10.12. září 1999 \{VIII. tschechischer Historikertag Hradec Králové/Königgrätz, 10.-12. September 1999\} (Praha 2000) 178-189.

Bohuslav ROUČKA, Poznámky k mapě hrdelních soudů v první a ve druhé polovině 18 . století \{Anmerkungen zur Karte der Halsgerichte in Böhmen in der ersten und zweiten Hälfte des 18. Jahrhunderts\}, in: PHS 3 (1957) 115-135.

Renáta RŮŽIČKOVÁ, Tereza SIGLOVÁ, Apelační soud a odvolání proti rozhodnutím nižších soudio pardubického panství (Případy řešené $\mathrm{v}$ civilním soudním řízení v 16.-18. století) \{Das Appellationsgericht und die Berufungen gegen Entscheidungen der niederen Gerichte der Herrschaft Pardubitz (Entscheidungen in zivilrechtlichen Streitfällen im 16.-18. Jahrhundert)\}, in: Sborník prací východočeských archivů 13 (2009) 13-130.

DIES., Apelační soud a případy řešené v inkvizičním soudním řízení na pardubickém panství v 16.18. století \{Das Appellationsgericht und die in der Herrschaft Pardubitz im Inquisitionsverfahren entschiedenen Streitfälle im 16.-18. Jahrhundert\}, in: Sborník prací východočeských archivů 14 (2010) 13-110.

Marie RyantovÁ, Ladislav II. Popel z Lobkovic jako první president apelačního soudu \{Ladislaus II. Popel von Lobkowitz als erster Präsident des Appellationsgerichts\}, in: VOREL, Stavovský odboj 185-204.

Boris ŠALAK, Apelační soud v letech 1749-1790 (1850) \{Das Appellationsgericht in den Jahren 1749-1790 (1850)\} (phil. Dipl.arbeit, KUP 2011).

Johann Ferdinand SCHMIDT, Monographie des kaiserl. königl. Böhm. Appellations-Gerichtes seit dessen Errichtung als Appellationskammer in dem Jahre 1548 bis zu dessen im Jahre 1850 erfolgter Umwandlung in das kais. kön. Oberlandesgericht des zu dem constitutionellen Kaiserthume Oesterreich gehörigen Kronlandes Böhmen (Prag 1850).

SNĚMY české od léta 1526 až po naši dobu \{Die böhmischen Landtage vom Jahre 1526 bis in unser Zeitalter\}, Bd. 2, Bd. 4 (Praha 1880-1886).

Václav Šolle, Trestní soudnictví předbřeznové v českých zemích \{Die Strafgerichtsbarkeit in den böhmischen Ländern im Vormärz\}, in: Sborník archivních prací 12 (1962) 87-142.
Dagmar STUPKOVÁ, Apelační a vrchní zemský soud v Praze 1783-1850. Inventář fondu \{Appellationsund Oberlandesgericht in Prag 1783-1850. Inventar des Archivfonds\} (Praha 1982).

Theresiana siehe Constitutio Criminalis Theresiana

Václav VANĚČEK, Dějiny státu a práva v Československu \{Staats- und Rechtsgeschichte in der Tschechoslowakei\} (Praha ${ }^{31976) . ~}$

Jiří VESELÝ, O přenesení působnosti hejtmanství německých lén na apelační soud na Hradě pražském \{Die Übertragung der Zuständigkeit der deutschen Lehenhauptmannschaft an das Appellationsgericht auf der Prager Burg\}, in: PHS 26 (1984) 73-92.

DERS., O soudu hejtmanství německých lén \{Über das Gericht der deutschen Lehenhauptmannschaft\}, in: PHS 16 (1971) 113-124.

Petr Vorel (Hg.), Stavovský odboj roku 1547. První krize habsburské monarchie. Sborník příspěvků z konference konané v Pardubicích 29. a 30. záŕí 1997 \{Der ständische Aufruhr im Jahre 1547. Die erste Krise der Habsburgermonarchie. Sammelband der Beiträge der Konferenz in Pardubice am 29. und 30. September 1997\} (Pardubice-Praha 1999).

Zikmund WINTER, Kulturní obraz českých měst. Život veřejný v XV. a XVI. věku \{Kulturbild der böhmischen Städte. Öffentliches Leben im XV. und XVI. Jahrhundert\}, Teil 2 (Praha 1892).

Klára WoITschová, Edice nebo databáze? Ortelní manuály jako komplementární pramen k poznání raně novověkého městského soudnictví \{Edition oder Datenbank? Die Urteilsmanuale als komplementäre Quelle zur Erforschung der frühneuzeitlichen Stadtgerichtsbarkeit\}, in: HRUBÁ, SULITKOVÁ, ZÁBRANSKÝ, Stav a perspektivy 241-252.

DIES., Obraz činnosti pražského apelačního soudu v letech 1672-1682 ve světle ortelních manuálů a knih protokolů \{Ein Bild der Tätigkeit des Prager Appellationsgerichtes in den Jahren 1672-1682 im Lichte der Urteilsmanuale und Protokollbücher\}, in: Paginae historiae 19 (2011) 96-115.

DiES., Ortelní manuály a knihy protokolů apelačního soudu v Praze z let 1548-1783 \{Die Urteilsmanuale und Protokollbücher des Appellationsgerichtes in Prag aus den Jahren 1548-1783\}, in: Paginae historiae 16 (2008) 545-558.

Václav ZDENĚK, Dějiny král. Apellačního soudu na hradě Pražském, nyní vrchního soudu v Praze od roku 1548-1933 \{Geschichte des königl. Appellationsgerichts an der Prager Burg, derzeit Obergericht in Prag 1548-1933\} (Praha 1933). 


\section{Zusammenfassung}

Das Appellationsgericht in Prag wurde 1548 von König Ferdinand I. gegründet. Nach der anlässlich seiner Gründung erlassenen Instruktion sollte es ein Appellationsgericht für alle Stadtgerichte in den Ländern der Böhmischen Krone (Böhmen, Mähren, Schlesien und beide Lausitzen) sein. In der Praxis allerdings arbeitete das Appellationsgericht zunächst hauptsächlich als Appellationsgericht für die Stadtgerichte im Königreich Böhmen und (bis 1621) in den Lausitzen. In der ersten Hälfte des 17. Jahrhunderts erweiterte sich seine Tätigkeit auf einige schlesische Fürstentümer. Für Mähren war das Appellationsgericht nur in der Zeitspanne zwischen dem Ende des 17. und der Mitte des 18. Jahrhunderts von Bedeutung. Das Appellationsgericht verschwand im Zuge der Justizreformen unter Kaiser Joseph II.; es wurde zum Allgemeinen Appellationsgericht umgewandelt und damit auch höchster Strafgerichtshof für das Königreich Böhmen. Der vorliegende Beitrag gibt einen Überblick über Forschung (1) und Quellen (2) zur Geschichte des Appellationsgerichts in Prag, außerdem über seine Geschichte, seine Tätigkeit, seine Zuständigkeit und sein Personal (3).

\section{Summary}

The Court of Appeal in Prague was established by King Ferdinand I in 1548. According to its founding statute, it was supposed to be a Court of Appeal for all municipal courts in the lands of the Bohemian Crown (Bohemia, Moravia, Silesia and both Lusatias). In practice, however, the Court of Appeals initially functioned first of all as a Court of Appeal for the municipal courts in the Kingdom of Bohemia and, until 1621, the Lusatian lands. Since the first half of the 17th century, its field of action expanded to some of the Silesian principalities. For Moravia, the Court of Appeal was important only for the period between the end of the $17^{\text {th }}$ and the middle of the $18^{\text {th }}$ century. The Court of Appeal disappeared in the course of Emperor Joseph II's judicial reform, when it was transformed into the High Court of Appeals, which was also the highest criminal court for the Kingdom of Bohemia. The article provides an overview of the research (1) as well as the sources elucidating the history of the Court of Appeal in Prague (2). It also outlines its history, including information on the Court's activities, its competence, and its personnel (3). 